\title{
Unsuspected thyrotoxicosis and hyperemesis gravidarum in Asian women
}

\author{
Wang Chong, Colin Johnston
}

\begin{abstract}
Summary
This report describes three women with hyperemesis gravidarum caused by previously undiagnosed thyrotoxicosis. All three women were eight weeks pregnant and only one woman had typical features of thyrotoxicosis. Hyperemesis could not be controlled by anti-emetics. The patients were successfully treated with antithyroid drugs. Anti-thyroid treatment does not need to be continued once resolution of symptoms and thyrotoxicosis have occurred.
\end{abstract}

Keywords: thyrotoxicosis, hyperemesis gravidarum, Asian women

The majority of women experience vomiting $(59 \%)$ and nausea $(70 \%)$ during the first trimester of pregnancy. ${ }^{1}$ Hyperemesis can be defined as persistent vomiting of such severity as to render the patient unable to maintain adequate hydration. If the problem is sufficiently severe and prolonged, fluid and electrolyte as well as nutritional status may become compromised. Hyperemesis occurs in $0.1 \%$ of pregnancies $^{2}$ and has been described in association with thyrotoxicosis. ${ }^{3-7}$ Thyrotoxicosis is relatively uncommon in pregnancy and is usually due to Graves' disease, often presenting before pregnancy. Vomiting may be a feature of untreated thyrotoxicosis. ${ }^{3,4,6} \mathrm{We}$ report three cases of hyperemesis gravidarum caused by previously undiagnosed thyrotoxicosis. In two of the cases, thyrotoxicosis was not clinically apparent.

\section{Case reports}

Case 1

A 25-year-old Pakistani woman who was eight weeks pregnant was admitted to hospital with hyperemesis gravidarum and palpitations. She had previously been well. In her last pregnancy she suffered from hyperemesis gravidarum for six months. There was no family history of thyroid disease. On admission she looked miserable but was apyrexial. There was a sinus tachycardia and a diffuse smooth goitre with a soft bruit but no ophthalmopathy. Thyrotoxicosis was confirmed by a suppressed thyrotropin <0.1 mU/1 (normal 0.32-5.00 mU/1), a high thyroxine $\left(\mathrm{T}_{4}\right) 277 \mathrm{nmol} / 1$ (normal $60-$ $140 \mathrm{nmol} / \mathrm{l}$ ), and a high total triiodothyronine $\left(\mathrm{T}_{3}\right) 6.44 \mathrm{nmol} / 1$ (normal $1.10-3.20 \mathrm{nmol} / \mathrm{l}$ ). Urea, electrolytes, liver function and gastro- scopy were normal. She was rehydrated with intravenous fluids, but despite prochlorperazine, cyclizine and domperidone, she continued to vomit for nine days after admission, until she started carbimazole $20 \mathrm{mg}$ bid and propranolol $40 \mathrm{mg}$ bid. Within seven weeks of treatment, her thyrotropin rose to $1.51 \mathrm{mU} / 1$, $\mathrm{T}_{4}$ fell to $95 \mathrm{nmol} / \mathrm{l}$ and total $\mathrm{T}_{3}$ fell to 4.25 $\mathrm{nmol} / \mathrm{l}$. Antimicrosomal and anti-thyroglobulin antibodies were negative. Carbimazole was gradually reduced but continued until three weeks postpartum, following which the mother has remained euthyroid off treatment. The baby is euthyroid and well.

Case 2

A 31-year-old Kashmiri woman who was nine weeks pregnant was admitted to hospital with a three-week history of nausea and vomiting, and a one-week history of hyperemesis. She had previously been well and her three previous pregnancies had been uneventful. There was no family history of thyroid disease. On admission she was sweaty, apyrexial, heart rate was 84 beats/min and regular, and reflexes were normal. There was no ophthalmopathy and no goitre. She was rehydrated with intravenous fluids but her vomiting was only partially relieved by metoclopramide. Thyrotoxicosis was confirmed by a thyrotropin $<0.1 \mathrm{mU} / 1$ and a $\mathrm{T}_{4}$ of $283 \mathrm{nmol} / 1$. Antimicrosomal and anti-thyroglobulin antibodies were not detected. Urea, electrolytes and liver function were normal. A gastroscopy revealed a small hiatus hernia but no other lesion. Her vomiting resolved and anti-thyroid treatment was withheld. She was discharged and observed in the out-patient clinic. One month later, her thyrotropin was $0.11 \mathrm{mU} / \mathrm{l}, \mathrm{T}_{4} 153$ $\mathrm{nmol} / 1$ and total $\mathrm{T}_{3} 2.69 \mathrm{nmol} / \mathrm{l}$. She is nearing the end of her pregnancy and remains clinically and biochemically euthyroid.

Case 3

A 29-year-old Bangladeshi woman who was nine weeks pregnant was admitted to hospital with a four-day history of hyperemesis gravidarum unresponsive to prochlorperazine. She had previously been well, although she required admission to hospital in one of her four previous pregnancies because of her hyperemesis gravidarum. There was no family history of thyroid disease. On admission she was clinically dehydrated. Pulse was 96 beats/min and regular. There was no ophthalmopathy and no goitre. She was rehydrated with intravenous fluids and her vomiting settled with cyclizine, 
although her nausea continued. Her thyrotropin was $<0.1 \mathrm{mU} / \mathrm{l}, \mathrm{T}_{4}$ was $307 \mathrm{nmol} / 1$ and liver function was impaired (bilirubin $82 \mu \mathrm{mol} /$ 1 [normal $0-17 \mu \mathrm{mol} / \mathrm{l}$ ], aspartate transaminase $102 \mathrm{IU} / 1$ [normal $0-40 \mathrm{IU} / 1$ ], gammaglutamyl transpeptidase 267 IU/1 [normal 0$35 \mathrm{IU} / 1]$ ). She was treated with propylthiouracil $200 \mathrm{mg}$ od and within six weeks her thyrotropin was $0.18 \mathrm{mu} / \mathrm{l}, \mathrm{T}_{4} 119 \mathrm{nmol} / \mathrm{l}$, and total $\mathrm{T}_{3} 3.46 \mathrm{nmol} / \mathrm{l}$. Antimicrosomal and anti-thyroglobulin antibodies were not detected. The propylthiouracil was successfully reduced over a one-month period. There has been no further relapse of her hyperemesis gravidarum. She has remained clinically and biochemically euthyroid, and her propylthiouracil has been stopped.

\section{Discussion}

We have described three cases of hyperemesis gravidarum associated with thyrotoxicosis. Cases one and three had hyperemesis in their previous pregnancies. Case one had typical features of thyrotoxicosis, but cases two and three did not. Case one had a goitre, but none of the cases had ophthalmopathy and none had atrial fibrillation. All three cases were Asian, although our clinic population was predominantly Caucasian. None of the cases gave a personal or family history of thyroid disease, or of any other autoimmune endocrine disorder. In each case, the antimicrosomal and antithyroglobulin antibody titres were negative and there was no clinical evidence of Graves' disease.

An association between hyperemesis gravidarum and abnormal thyroid function has been described. ${ }^{3-7}$ This association was not demonstrated in a UK series, ${ }^{8}$ but this may have been due to racial differences. Kennedy et $a l,{ }^{6}$ described a series of patients presenting with thyrotoxicosis and hyperemesis gravidarum who were all Asian, as were patients in three other case reports. ${ }^{3-5}$ Lao et al ${ }^{6}$ reported a Chinese woman with transient hyperthyroidism in hyperemesis gravidarum. In the series by Goodwin et al, ${ }^{7} 63$ out of 67 patients (95\%) were Hispanic. We have no known explanation for these racial differences. The aetiology of thyrotoxicosis is also unclear as it may be recurrent ${ }^{4,6}$ (cases one and three), and does not appear to be autoimmune..$^{4,6,7}$ It is possibly a transient thyroiditis.

The role of anti-thyroid medication remains unclear. All three of our cases improved, and in two, this improvement appeared to be associated with anti-thyroid medication and an improvement in thyroid function. Goodwin et $a l^{7}$ however, suggested that improvement usually occurs without the need for antithyroid medication. Other authors ${ }^{1}$ have suggested a beneficial effect of high-dose

1 Nelson-Piercy C, De Swiet M. Corticosteriods for the treatment of hyperemesis gravidarum. Br $\mathcal{f}$ Obstet Gynaecol 1994; 101: 1013-5.

2 Fairweather DVI. Nausea and vomiting in pregnancy. $A m \mathfrak{F}$ Obstet Gynecol 1968; 102: 135-75. corticosteroids in the treatment of these patients, and have suggested that frequent abnormalities of thyroid function are an epiphenomenon related to the underlying condition, the so-called 'sick euthyroid' syndrome.' We do not, however, believe this to be the case. Contrary to the 'sick euthyroid' syndrome, our cases and those in the literature $^{7,9,10}$ had elevated levels of thyroid hormones. In all our cases, the thyroid hormone levels were well into the toxic range for such an early stage of pregnancy.

The apparent beneficial effect of corticosteroids in the treatment of hyperemesis does not exclude thyrotoxicosis in the aetiology. Amiodarone can induce thyrotoxicosis, and in some cases this is thought to be due to a thyroiditis, perhaps related to changes in circulating interleukin-6. ${ }^{11}$ Corticosteroids have been shown to be beneficial in the treatment of this form of thyrotoxicosis. ${ }^{11}$ It is, therefore, possible that the apparent beneficial effects of corticosteroids in the treatment of hyperemesis could, at least in part, be due to the effect on thyroid function. In our case three and in others, ${ }^{7}$ abnormalities of liver function have been described in hyperemesis. Such abnormalities have also been described in thyrotoxicosis. $^{12}$

No single explanation of hyperemesis has been described, but racial, social, nutritional, and psychological factors have been attributed as possible causes. ${ }^{2}$ It has been reported that hyperemesis may be related to the level of circulating human chorionic gonadotropin (hCG) ${ }^{2,13}$ Hyperemesis is associated with early pregnancy, is commoner in twin pregnancies, and with trophoblastic tumours, where serum hCG levels are higher. ${ }^{4,6}$ However, other authors have reported hCG levels within the normal range in all their hyperemetic patients. ${ }^{6,8}$

Hyperemesis gravidarum is commonly treated by fluid and electrolyte supplementation, and nutritional and psychological support. Many different pharmacological agents have been tried, including anti-emetics, antihistamines, histamine receptor blockers, omeprazole, ondansetron, and vitamin $\mathbf{B}_{6}$. The problems associated with severe hyperemesis should not be underestimated. Such cases may require total parenteral nutrition via a central venous catheter, and there are risks of Wernicke's encephalopathy secondary to thiamine (vitamin $B_{1}$ ) deficiency and fatal central pontine myelinosis caused by rapid reversal of hyponatraemia. Our experience would suggest that, in cases with proven abnormalities of thyroid function, anti-thyroid medication may be beneficial.

We thank Dr L Kane, Mr Y Tayob, and Mr D Rosenberg for allowing us to report on these cases.

3 Valentine $\mathrm{BH}$, Jones $\mathrm{C}$, Tyack AJ. Hyperemesis gravidarum due to thyrotoxicosis. Postgrad Med $\mathcal{f} 1980 ; 56: 746-7$.

4 Jeffcoate WJ, Bain C. Recurrent pregnancy induced thyrotoxicosis presenting as hyperemesis gravidarum. $B r f$ Obstet Gynaecol 1985; 92: 413-5. 
5 Kennedy RL, Darne J, Davies R, Price A. Thyrotoxicosis and hyperemesis gravidarum associated with a serum and hyperemesis gravidarum associated with a serum activity which stimulates hum

6 Lao TTH, Chin RKH, Cockram CS, Panesar NS Transient hyperthyroidism in hyperemesis gravidarum. $\mathfrak{F} R$ Soc Med 1986; 79: 613-5.

7 Goodwin TM, Montoro M, Mestman JH. Transient hyperthyroidism and hyperemesis gravidarum: clinical aspects. Am f Obstet Gynecol 1992; 167: 648-52.

8 Wilson $\mathrm{R}$, McKillop JH, MacLean M, et al. Thyroid function tests are rarely abnormal in patients with severe hyperemesis gravidarum. Clin Endocrinol 1992; 37: $331-4$.

9 Taylor R Successul management of hyperemesis gravidarum using steroid therapy. Of Med 1996; 89: $103-7$.

10 Krentz AJ, Redman H, Taylor KG. Hyperthyroidism associated with hyperemesis gravidarum. Br $f$ Clin Pract 1994; 48: $75-6$.
11 Bartalena L, Grasso L, Brogioni S, Aghini-Lombardi F, Braverman LE, Martino E. Serum interleukin-6 in amiodarone induced thyrotoxicosis. F Clin Endocrinol Metab 1994; 78: 423-7.

12 Beckett GJ, Kellett HA, Gow SM, Hussey AJ, Hayes JD, Toft AD. Raised plasma glutathione $S$-transferase values in hyperthyroidism and in hypothyroid patients receiving thyroxine replacement: evidence for hepatic damage. $B M F$ 1985; 291: 427-31.

13 Kauppila A, Huhtaniemi I, Ylikorkala O. Raised serum human chorionic gonadotrophin concentrations in hyperemesis gravidarum. BMf 1979; i: 1670-1.

\title{
Acute fulminant neuropathy in a patient with Churg-Strauss syndrome
}

\author{
KKP Ng, HM Yeung, KT Loo, HM Chan, CK Wong, PCK Li
}

\begin{abstract}
Summary
We report a patient with an acute neuropathy initially mimicking Guillain-Barré syndrome, both clinically and electrophysiologically. Persistent eosinophilia, positive antineutrophil cytoplasmic antibody and eosinophilic vasculitis in sural nerve biopsy later confirmed Churg-Strauss syndrome. Since vasculitic neuropathy can present in an acute and fulminant form, the role of early antibody testing and sural nerve biopsy in atypical cases of acute neuropathy is emphasized.
\end{abstract}

Keywords: Churg-Strauss syndrome, allergic granulomatous angiitis, neuropathy, Guillain-Barré syndrome

The peripheral nervous system is commonly involved in systemic vasculitic diseases such as polyarteritis nodosa, Churg-Strauss syndrome, Wegener's granulomatosis and cryo- globulinaemia. The incidence can be greater than $75 \%{ }^{1}$ Presentation is usually as mononeuritis multiplex, asymmetrical polyneuropathy, chronic distal symmetrical sensory or sensorimotor polyneuropathy. ${ }^{1-4}$ An acute fulminant involvement of all peripheral nerves in the early phase of illness is rarely reported.

\section{Case report}

A 58-year-old man had late-onset asthma for the past two years which was well controlled with a regular inhalational bronchodilator. $\mathrm{He}$ enjoyed good health otherwise. For six weeks before admission, he had had general malaise, night sweating, low-grade fever and weight loss. His general practitioner diagnosed pulmonary tuberculosis following a chest X-ray which showed bilateral apical infiltrates. He received anti-tuberculous drugs but stopped taking them after three days because of gastrointestinal upset. $\mathrm{He}$ was then admitted
Department of Medicine, Queen Elizabeth Hospital, Kowloon, Hong Kong

Division of Neurology $\mathrm{KKP} \mathrm{Ng}$

HM Yeung

HM Chan

CK Wong

PCK Li

Department of

Pathology

KT Loo

Accepted 27 June 1996

Table Results of nerve conduction study on day 3

\begin{tabular}{|c|c|c|c|c|c|c|c|}
\hline Nerve & $\begin{array}{l}D M L \\
\text { (ms) }\end{array}$ & $\begin{array}{l}C M A P \\
(m V)\end{array}$ & $\begin{array}{l}M N C V \\
(\mathrm{~m} / \mathrm{s})\end{array}$ & $\begin{array}{l}\text { Conductional } \\
\text { block }\end{array}$ & F-wave & $\begin{array}{l}S N A P \\
(\mu V)\end{array}$ & $\begin{array}{l}S N C V \\
(\mathrm{~m} / \mathrm{s})\end{array}$ \\
\hline $\mathbf{R}$ median & 3.7 & $4.9^{\star}$ & 52 & absent & normal & 10 & 45 \\
\hline L median & 3.9 & $2.3^{\star}$ & - & complete & absent & $3 *$ & 46 \\
\hline $\mathbf{R}$ ulnar & 2.6 & $1.1^{\star}$ & $48^{\star}$ & absent & absent & $4^{\star}$ & 48 \\
\hline L ulnar & 3.2 & 11.0 & 52 & absent & prolonged & $5^{\star}$ & 46 \\
\hline $\mathbf{R}$ peroneal & 3.5 & $0.6^{\star}$ & 42 & absent & prolonged & & \\
\hline $\mathrm{L}$ peroneal & 4.2 & $1.3^{\star}$ & 41 & partial & absent & & \\
\hline $\mathrm{R}$ posterior tibial & 6.3 & $0.07^{\star}$ & 60 & partial & absent & & \\
\hline L posterior tibial & 5.1 & $0.7^{\star}$ & 41 & partial & absent & & \\
\hline$R$ sural & & & & & & 7 & 57 \\
\hline L sural & & & & & & 13 & 50 \\
\hline
\end{tabular}

Abbreviations: $\mathrm{R}=$ right; $\mathrm{L}=$ left; $\mathrm{DML}=$ distal motor latency; $\mathrm{CMAP}=$ compound muscle action potential amplitude $M N C V=$ motor nerve conduction velocity; $S N A P=$ sensory nerve action potential amplitude; $S N C V=$ sensory nerve conduction velocity; ${ }^{\star}$ abnormal values 